\title{
Propiconazole nanoencapsulation in biodegradable polymers to obtain pesticide-controlled delivery systems.
}

Felipe Barrera-Méndez ${ }^{1,2 *}$, Diter Miranda-Sánchez ${ }^{1}$, Diana Sánchez-Rangel ${ }^{1,2}$, Israel Bonilla-Landa ${ }^{1}$, Benjamín Rodríguez-Haas ${ }^{1}$, Juan Luis Monribot-Villanueva ${ }^{1}$, José Luis Olivares-Romero ${ }^{1}$.

${ }^{1}$ Red de Estudios Moleculares Avanzados, Instituto de Ecología AC, Xalapa, Veracruz, México.

${ }^{2}$ Cátedra CONACYT en el Instituto de Ecología AC, Xalapa, Veracruz, México.

*Corresponding author: Felipe Barrera-Méndez, e-mail: felipe.barrera@inecol.mx. Red de Estudios Moleculares Avanzados, Instituto de Ecología AC, Xalapa, Veracruz, México. Cátedra CONACYT en el Instituto de Ecología AC, Xalapa, Veracruz, México.

Received May 16 ${ }^{\text {th }}, 2018$; Accepted March $16^{\text {th }}, 2019$.

DOI: http://dx.doi.org/10.29356/jmcs.v63i1.564

\begin{abstract}
The nanoencapsulation of pesticides in biodegradable polymers confers several advantages to conventional agrochemicals, such as protection against losses due volatilization and degradation of the active ingredient, as well as the augment of water dispersion, allowing for their application on crops without requiring the use of organic solvents that could harm the user and the environment. These characteristics could enhance the productivity, reducing both costs and environmental pollution. In this work the propiconazole fungicide, forming part of a commercial formulation as well as in its pure state, was encapsulated using as carriers the biodegradable polymer poly lactic acid (PLA) and the biodegradable co-polymer poly (lactic-co-glycolic) acid, all with the aim of generate systems of controlled release of fungicide to augment the efficiency of the treatments of the Fusarium dieback disease. The most efficient system obtained presented nanospheres of $146.28 \mathrm{~nm}$ and an encapsulation efficiency over $42 \%$. The antifungal activity tests showed that the use of this nanoencapsulated fungicide system enhances the growth inhibition percentage in 5\%, obtaining a formulation that presents good dispersion in water without the need of organic emulsifier agents. The release profile test showed that while the commercial formulation dialyzed 50 and $90 \%$ of the propiconazole in approximately 5 and 30 hours, respectively, it took the nanoencapsulated propiconazole almost twice as much time to dialyze the same percentage of load, effectively prolonging the availability of the fungicide without diminishing the antifungal activity.
\end{abstract}

Keywords: Nanooencapsulation; Propiconazole; Fungicide; Fusarium; Emulsification and solvent evaporation.

Resumen: La nanoencapsulación de pesticidas en polímeros biodegradables es una herramienta que confiere varias ventajas a los agroquímicos, tales como protección contra pérdidas por volatilización y degradación del ingrediente activo, y el aumento de dispersión en agua, permitiendo ser aplicados en cultivos sin requerir el uso de solventes orgánicos dañinos para el usuario y el medio ambiente. Estas partículas podrían mejorar la productividad y al mismo tiempo reducir costos y contaminación ambiental. En este trabajo se nanoencapsuló el fungicida propiconazol, tanto formando parte de una formulación comercial como en su forma pura, utilizando el polímero biodegradable ácido poliláctico y el copolímero biodegradable ácido poli (láctico-co-glicólico) como materiales acarreadores, todo con el fin de generar sistemas de liberación controlada de fungicidas para aumentar la eficiencia en los tratamientos de la enfermedad de muerte regresiva por Fusarium. El sistema más efectivo obtenido arrojó nanoesferas de $146.28 \mathrm{~nm}$ y una eficiencia de captura sobre el $42 \%$. Las pruebas de actividad antifúngica revelaron que el utilizar este sistema de fungicida nanoencapsulado aumenta el porcentaje de inhibición de crecimiento del hongo Fusarium solani en 5\%, obteniendo así una formulación que presenta buena dispersión en agua sin requerir de agentes emulsificantes orgánicos. Las pruebas de perfil de liberación mostraron que mientras la formulación comercial dializó el 50 y $90 \%$ de su carga en aproximadamente 5 y 30 horas, respectivamente, le tomó al propiconazol nanoencapsulado casi el 
doble de tiempo para dializar el mismo porcentaje de carga, prolongando efectivamente la disponibilidad del fungicida sin disminuir su actividad antifúngica.

Palabras Clave: Nanoencapsulación; Fungicida; Propiconazol; Emulsificación y evaporación de solvente; Fusarium.

\section{Introduction}

In the second half of the XX century the farmers have been in the need of supply an unprecedented augment of food demand. This encouraged the intensive use of pesticides, many of which are synthetic and with a very high efficiency. Nevertheless, as time went by, there have been observed serious environmental effects as a consequence of the use of such chemicals [1]. Due the continuous growth of the population, there is a critical necessity of getting a better food production and maintain the food safety worldwide. Since plant pathogen fungi could significantly jeopardize the crop production, fungicides are commonly applied to prevent their propagation, raising the concern for the negative impact of these pesticides on human health [2]. In addition of the bacterial and viral pathogens, the fungal plant pathogens are the principal contributors to the severe production loss. The most important challenges that the global agriculture is facing includes climatic change, urbanization, sustainable use of natural resources, environmental problems like the accumulation of pesticides and fertilizers, and a higher resistance of the pathogenic fungi to fungicides [3]. The worldwide consumption of pesticides is approximately two million tons per year out of which $45 \%$ is used by Europe alone, $25 \%$ is consumed in the USA and $25 \%$ in the rest of the world, but the indiscriminate use of pesticides enhances the resistance to pathogens, kills soil bacteria and pollinators and destroys the natural habitat [4].

One of these agrochemicals, Propiconazole, is a fungicide used for the control of the Fusarium Dieback disease, caused by the Fusarium euwallaceae fungus, which impacts in avocado-growing regions in southern California [5]. Since nearly $90 \%$ of applied pesticides are either lost in the environment or unable to reach the target area, in order to achieve the desired biological response in terms of pest control within a given period such chemicals are used in quantities greatly exceeding the amount actually required to control the target pests. These losses occur due to factors such as application techniques, physicochemical properties of the pesticides, and environmental conditions [6]. The remaining losses are the result of leaching, evaporation, deposition, being washed away, and degradation by photolysis, hydrolysis, and microbial activity [7].

Nanotechnology could have a substantial impact on sustainable agriculture and the development of precision agriculture. The ultimate purpose is to maximize the agricultural production, in other words, crops performance, while at the same time the use of fertilizers and pesticides is minimized by monitoring environmental variables and the application of specific measures. In this perspective, the objective of manage a sustainable agriculture is more important than the necessity for the development of a "green nanotechnology", an approach to equilibrate the benefits of the nanoproducts on solutions for environmental challenges with the evaluation and management of environmental resources [8]. Among such technological innovations, nanotechnology is achieving notable consideration due its robust application on agriculture [9].

Using this technology in pesticide delivery has created many opportunities for safe application of conventional pesticides, for example, nanoencapsulation of pesticides to obtain agrochemical delivery systems, involving the formation of pesticide-loaded particles or -entrapped particles having a diameter within the nanorange [10]. According to the definition of nanoparticle, this size range should be between 1 to $100 \mathrm{~nm}$ in at least one dimension [11]. Nevertheless, the term "nano" for encapsulated pesticides may be referred to a particle size bigger than $100 \mathrm{~nm}$. This may be based on the efficacy and applications of their novel small-sized particulate and not only in their size [12]. The large surface area obtained increases the affinity to the target species and reduces the pesticide required for pest control [13]. Nanocarrier materials, such as biodegradable polymers, also protect the active ingredient from premature degradation and allow them to be released in a controlled way [14]. Polylactic acid (PLA) and Poly(lactic-co-glycolic) acid (PLGA) are two polymers that have been used as nanocarriers for delivery systems [15], since their biodegradation by-products are non-toxic [16]. Previous studies suggest that the biodegradation in soil of these polymers could take up to several months [17], leaving the molecular diffusion as the dominant mechanism of fungicide liberation to the medium. The aim of this study is to obtain a nanoencapsulated propiconazole delivery system to reduce costs in the treatment of the Fusarium Dieback disease. 


\section{Experimental}

\section{Materials and Methods}

Commercial fungicide formulation Prosan ${ }^{\circledR}(250 \mathrm{~g}$ of propiconazole/L) industrial grade poly lactic acid filament for 3D printer (Marker Bot), reagent grade poly (lactic-co-glycolic) acid 50:50 (Mw 30,000- 60,000) (Sigma-Aldrich), reagent grade acetone (Sigma-Aldrich), reagent grade sodium citrate tribasic (Sigma-Aldrich), reagent grade poly vinyl alcohol (Mw 89,000- 98,000) (Sigma-Aldrich), industrial grade dichloromethane (Pochteca), Silica gel 400-600 mesh (Merck), reagent grade phosphomolybdic acid (Sigma-Aldrich), industrial grade isopropanol (Pochteca), industrial grade ethanol (VWR chemicals), acetonitrile HPLC grade (Sigma-Aldrich), and Milli-Q water.

The industrial grade solvents were previously distilled before been used in the experiments. The nanoencapsulation of the fungicide was performed using the emulsification and solvent evaporation technique [18]. Dichloromethane (DCM) and acetone were tested as the solvents for the organic phase, PLA and PLGA were tested as the biodegradable carrier, sodium citrate and poly vinyl alcohol (PVA) were tested as the emulsion stabilizer, and the commercial formulation Prosan ${ }^{\circledR}$ and purified propiconazole were tested as the encapsulated agents.

\section{Biological material}

A Fusarium solani strain was used for the antifungal assays due its phylogenetic closeness to $F$. euwallaceae. The $F$. solani INECOL_BM-04 strain was provided by the Molecular Biology laboratory at the Clúster Científico y Tecnológico BioMimic ${ }^{\circledR}$, México. The strain was grown on Petri dishes with potato dextrose agar (PDA) at $28 \pm$ $1^{\circ} \mathrm{C}$ with periodic subculturing.

\section{Purification of propiconazole}

Propiconazole was purified from $15 \mathrm{~mL}$ of the commercial formulation Prosan ${ }^{\circledR}$ by open column chromatography. Silica gel of 400-600 mesh was used as the stationary phase, while a mixture of DCM and isopropanol (98:2) was used as the mobile phase. Thin layer chromatography was used to determinate the fractions where the propiconazole was present without contaminants, using phosphomolybdic acid as the visualization reagent. Finally, the solvents were removed by rotaevaporation at $40{ }^{\circ} \mathrm{C}$ and $660 \mathrm{mBar}$. The purity of the obtained compound was confirmed by the nuclear magnetic resonance spectroscopy (NMR) technique using a Bruker Avance III HD spectrometer running a $500 \mathrm{MHz}$ for ${ }^{1} \mathrm{H}$ and $125 \mathrm{MHz}$ for ${ }^{13} \mathrm{C}$ and high resolution mass spectrometric analysis was performed using a quadrupole-time of flight (Q-TOF) mass spectrometer equipped with an electrospray ionization (ESI) interface (Synapt G2-Si, Waters Inc.).

\section{Preparation of Stock Aqueous Solutions}

The aqueous phase in the experiments consisted in the dissolution of an emulsion stabilizer in Milli-Q water. The concentration for the tested stabilizers used for the emulsification process were $1 \mathrm{mM}$ for the sodium citrate and $1 \% \mathrm{w} / \mathrm{v}$ for the PVA. In order to avoid precipitation of the nanoparticles during the washing process, washing solution were prepared by diluting each aqueous solution ten times, obtaining a concentration of $0.1 \mathrm{mM}$ for sodium citrate washing solution and $0.1 \% \mathrm{w} / \mathrm{v}$ for PVA washing solution.

\section{Preparation of Stock Organic Solutions}

Each organic solution tested was used as the organic phase during the emulsification process, having a concentration of $5 \mathrm{mg} / \mathrm{mL}$ of the biodegradable polymeric carrier (either PLA or PLGA) dissolved in one of the two solvents tested (either acetone or DCM).

\section{Encapsulation of fungicide by the emulsification and solvent evaporation technique}

For each emulsion prepared, $5 \mathrm{~mL}$ of the organic phase were measured and $10 \mathrm{mg}$ of the agent to encapsulate (either $10 \mathrm{mg}$ of pure propiconazole or $40 \mu \mathrm{L}$ of the Prosan ${ }^{\circledR}$ formulation) were incorporated by magnetic steering. The organic phase was then added to $15 \mathrm{~mL}$ of the aqueous phase (emulsion stabilizer in Milli-Q water). The emulsion was obtaining using an ultrasonic processor applying $70 \%$ of amplitude in three intervals of 10 seconds. To avoid the violent boiling of the organic solvent, between each interval the emulsion rested in ice for 10 seconds. Finally, the organic solvent was removed by rotaevaporation, obtaining solid nanospheres of the tested carrier suspended in water. Fig. 1 shows the schematics of the nanoencapsulation process. Table 1 shows the different formulations tested. For the systems that managed to encapsulate the fungicide, the encapsulation was performed in 
triplicate and the obtained nanospheres were characterized by the dynamic light scattering and scanning electron microscopy techniques to calculate their respective average particle size and zeta potential, and to observe their morphology.
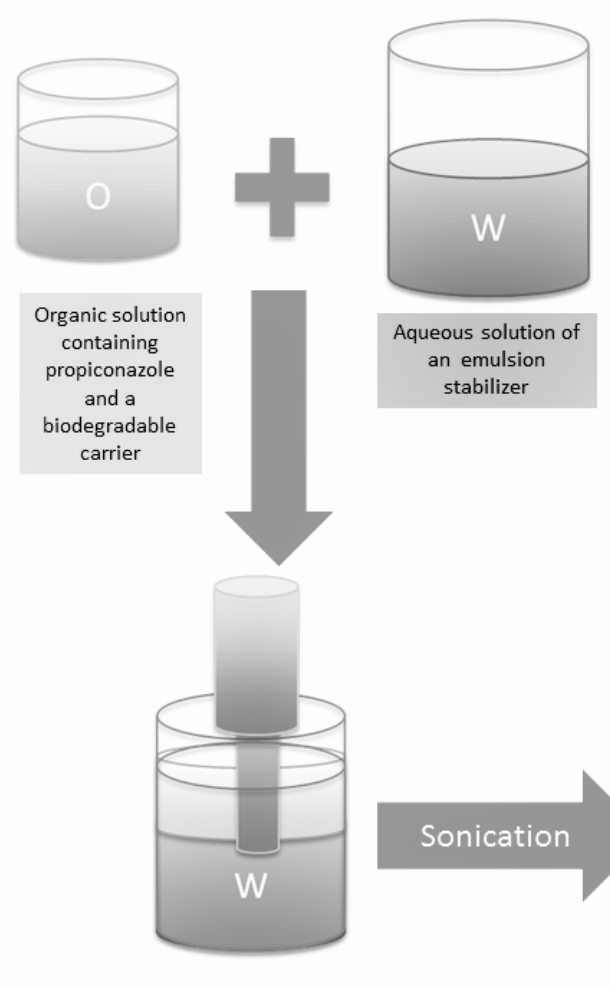

Fig. 1. Schematics of the emulsification and solvent evaporation technique.

Table 1. Formulations tested in the nanoencapsulation experiment.

\begin{tabular}{|c|c|c|c|c|}
\hline Formulation & Carrier & Organic Solvent & Encapsulated Agent & Emulsion Stabilizer \\
\hline 1 & PLGA & Acetone & Prosan ${ }^{\circledR}$ & Sodium Citrate \\
\hline 2 & PLGA & Acetone & Propiconazol & PVA \\
\hline 3 & PLA & DCM & Prosan ${ }^{\circledR}$ & Sodium Citrate \\
\hline 4 & PLA & DCM & Propiconazol & PVA \\
\hline 5 & PLGA & DCM & Prosan ${ }^{\circledR}$ & Sodium Citrate \\
\hline 6 & PLGA & DCM & Propiconazol & PVA \\
\hline
\end{tabular}

\section{Washing of nanospheres}

In order to remove the fraction of fungicide that was not able to be encapsulated, the nanospheres were washed by centrifugation at $5,000 \mathrm{x}$ g for 30 minutes. Once the supernatant was discarded, the nanospheres were resuspended in similar volume of the washing solution corresponding to the emulsion stabilizer used during the encapsulation. The washing process was performed 3 times for each encapsulation, re-suspending the last sediment to a final volume of $10 \mathrm{~mL}$.

\section{Determination of encapsulation efficiency}

In order to measure the amount of encapsulated propiconazole, the nanospheres had to release their load in ethanol. To achieve this, $1 \mathrm{~mL}$ of nanospheres solution was centrifuged at 5,000 x g for 30 minutes to remove the 
water. The next step was the addition of $1 \mathrm{~mL}$ of ethanol and sonication in ultrasonic bath for 30 minutes. After that, the nanospheres were centrifuged at 16,000 $\mathrm{x}$ for 30 minutes. Finally, the ethanol was collected and the amount of released propiconazole was measured by high performance liquid chromatography (HPLC; Perkin Elmer Flexar) with a UV detector monitoring at $220 \mathrm{~nm}$. The column used was Spheri-5 RP-18, $5 \mu, 250 \times 4.6 \mathrm{~mm}$ from Brownlee Columns. The column temperature was set at $30{ }^{\circ} \mathrm{C}$ and the mobile phases were water (A) and acetonitrile (B), both in HPLC grade (Sigma-Aldrich). The elution gradient was: $1 \mathrm{~min}$ in isocratic condition at $80 \%$ of A, $20 \mathrm{~min}$ in a linear gradient from 80 to $20 \%$ of A, 4 min in isocratic condition at $20 \%$ of A and finally 10 min in a linear gradient from 20 to $80 \%$ of A. The flow was stablished at $2 \mathrm{~mL} / \mathrm{min}$ and $10 \mu \mathrm{L}$ of sample was injected. A calibration curve was constructed with the area data of 10 concentration points $(0.025,0.05,0.075,0.1,0.2,0.3,0.4,0.6,0.8$ and 1 $\mathrm{mg} / \mathrm{mL}$ ) and each point was injected by triplicate. A linear regression method was applied, obtaining a determination coefficient of 0.99. The data was processed with the Perkin Elmer Chromera ${ }^{\circledR}$ software version 4.1.3.6412.

The encapsulation efficiency (EE) was calculated using the following equation:

$$
E E=\frac{P_{R}}{P_{0}} * 100
$$

where $\mathrm{P}_{0}$ is the propiconazole mass used in the encapsulation process and $\mathrm{P}_{\mathrm{R}}$ is the propiconazole mass released during the experiment.

\section{Propiconazole release profile}

A volume of nanospheres containing $5 \mathrm{mg}$ of propiconazole were dialyzed in an acetic acid solution (pH 5) for 4 days at $28 \pm 1{ }^{\circ} \mathrm{C}$, using $12-14 \mathrm{kD}$ dialysis membrane tubing. The duration and conditions of $\mathrm{pH}$ and temperature of the experiment were set to emulate those of the antifungal activity essay. The sum of the volume to be dialyzed (inside the membrane) and the volume of the release medium (outside the membrane) were adjusted to a total of 125 $\mathrm{mL}$. The amount of dialyzed propiconazole and the volume of the release medium were set to get a final concentration of $0.04 \mathrm{mg} / \mathrm{mL}$, well below than the reported solubility for the propiconazole in water at $25^{\circ} \mathrm{C}(0.1$ $\mathrm{mg} / \mathrm{mL}$ ). Aliquots of $0.5 \mathrm{~mL}$ were taken from the medium at different time intervals, replenishing each time the $\mathrm{ml}$ extracted with fresh acid solution in order to maintain a constant volume. The same procedure was applied to $20 \mu \mathrm{L}$ of the commercial fungicide (containing $5 \mathrm{mg}$ of propiconazole), to be used as a control. The amount of propiconazole present in the aliquots was measured by UV-Vis spectrophotometry using a Thermo Scientific spectrophotometer, model Genesys 10S.

\section{Antifungal activity}

For this essay, $4 \mu \mathrm{L}$ of conidia suspension of $F$. solani were inoculated in the center of each well of a 12-well cell culture plates with $1 \mathrm{~mL}$ of solid PDA (potato-dextrose-agar) culture media supplemented and $100 \mu \mathrm{M}$ of the propiconazole present in the system that showed the best encapsulation efficiency. The plates were incubated at $28 \pm$ $1{ }^{\circ} \mathrm{C}$ in completed darkness for 5 days. Solid PDA culture media were used as negative controls, while solid PDA culture media supplemented with commercial fungicide $100 \mu \mathrm{M}$ was used as positive control. We evaluated the solid PDA culture media supplemented with empty PLA nanoparticles. The concentration of empty PLA nanoparticles was the same as that of the PLA present in the nanocapsules used to reach $100 \mu \mathrm{M}$ of nanoencapsulated propiconazole. The experiments were performed in triplicate. The antifungal activity was recorded at 4 days after the inoculation (dpi) with a camera (Nikon model 3200) and the area of fungus growth including controls were obtained with image analysis software Image $\mathrm{J}^{\circledR}$. At 4 dpi the antifungal activity of the system that presented the best encapsulation efficiency was evaluated and the percentage of growth and percentage of inhibition of the growth the fungal was calculated with the growth inhibition percentage (GIP).

$$
G I P(\%)=100-\left[\frac{A_{i}}{A_{c}}\right] x 100
$$

where $A_{c}$ is the growth area of the fungus in the negative control well (full growth), and $A_{i}$ is the growth area of the fungus in the well exposed to the fungicide. 


\section{Results and discussions}

Pure propiconazole was obtained as a colorless oil containing both diastereoisomers. First diastereoisomer ${ }^{1} \mathrm{H}$ NMR $\left(500 \mathrm{MHz}, \mathrm{CDCl}_{3}\right) \delta 8.17(\mathrm{~s}, 1 \mathrm{H}), 7.90(\mathrm{~s}, 1 \mathrm{H}), 7.57(\mathrm{~d}, J=8.5 \mathrm{~Hz}, 1 \mathrm{H}), 7.45(\mathrm{~d}, J=0.9 \mathrm{~Hz}, 1 \mathrm{H}), 7.22(\mathrm{dd}$, $J=8.5,2.1 \mathrm{~Hz}, 1 \mathrm{H}), 4.73-4.67(\mathrm{~m}, 2 \mathrm{H}), 3.98(\mathrm{dd}, J=8.2,5.7 \mathrm{~Hz}, 1 \mathrm{H}), 3.72(\mathrm{ddd}, J=13.8,7.7,5.8 \mathrm{~Hz}, 1 \mathrm{H}), 3.34$ $(\mathrm{dd}, J=8.2,8.2 \mathrm{~Hz}, 1 \mathrm{H}), 1.40-1.20(\mathrm{~m}, 4 \mathrm{H}), 0.87(\mathrm{t}, J=7.1 \mathrm{~Hz}, 3 \mathrm{H}) .{ }^{13} \mathrm{C}(125 \mathrm{MHz}, \mathrm{CDCl} 3){ }^{13} \mathrm{C}$ NMR $(125$ $\left.\mathrm{MHz}, \mathrm{CDCl}_{3}\right) \delta 151.38,144.64,135.66,135.62,133.01,131.14,129.35,127.07,106.88,78.32,70.24,54.48,34.93$, 18.96, 13.91. HRMS (ESI) Calculated for $[\mathrm{M}+\mathrm{H}]^{+} 342.0771$ found 342.0792.

Second diastereoisomer ${ }^{1} \mathrm{H}$ NMR $\left(500 \mathrm{MHz}, \mathrm{CDCl}_{3}\right) \delta 8.20(\mathrm{~s}, 1 \mathrm{H}), 7.90(\mathrm{~s}, 1 \mathrm{H}), 7.54(\mathrm{~d}, J=8.4 \mathrm{~Hz}, 1 \mathrm{H}), 7.45(\mathrm{~d}, J$ $=0.8 \mathrm{~Hz}, 1 \mathrm{H}), 7.23(\mathrm{dd}, J=8.4,2.1 \mathrm{~Hz}, 1 \mathrm{H}), 4.75-4.67(\mathrm{~m}, 2 \mathrm{H}), 3.95-3.88(\mathrm{~m}, 2 \mathrm{H}), 3.19-3.14(\mathrm{~m}, 1 \mathrm{H}), 1.54-$ $1.34(\mathrm{~m}, 4 \mathrm{H}), 0.90(\mathrm{t}, J=7.2 \mathrm{~Hz}, 3 \mathrm{H}) .{ }^{13} \mathrm{C}$ NMR $\left(125 \mathrm{MHz}, \mathrm{CDCl}_{3}\right) \delta{ }^{13} \mathrm{C} \mathrm{NMR}\left(125 \mathrm{MHz}, \mathrm{CDCl}_{3}\right) \delta 151.27$, $144.73,135.74,134.85,133.09,131.30,129.56,127.13,106.80,76.67,70.24,54.03,34.49,18.94,13.91$. HRMS (ESI) Calculated for $[\mathrm{M}+\mathrm{H}]^{+} 342.0771$ found 342.0792 .

Some ${ }^{13} \mathrm{C}$ NMR peaks of the second diastereoisomer seem to have the same chemical shift due to overlap with those of the first diastereoisomer.

\section{Selection of formulations}

In preliminary tests, sodium citrate showed a bad interaction with the purified propiconazole, as it was unable to capture it inside the formed nanospheres. This behavior was detected again when testing Prosan ${ }^{\circledR}$ with PVA as stabilizer. Given this, the formulations that would use either purified propiconazole with sodium citrate, or Prosan ${ }^{\circledR}$ with PVA, were removed from the experimental design. Acetone as the organic solvent caused the polymer to precipitate once the organic and aqueous phases were mixed, discarding any formulation that used this solvent for future experimentation. Finally, formulation number 4 presented pelletization problems during the centrifugation, destroying the nanospheres in the process. All this made the formulations 3, 5 and 6 the only systems that achieved the nanoencapsulation of the fungicide. Only the system with the highest encapsulation efficiency was selected to be tested in the antifungal activity essay.

\section{Characterization of nanospheres}

Table 2 shows the average particle size, zeta potential, and encapsulation efficiency for the formulations 3,5 and 6. Both particle size and zeta potential were obtained by the dynamic light dispersion technique, using a Malvern setaziser, model Nano ZS90. The formulations that encapsulated Prosan ${ }^{\circledR}$ ( 3 and 5) yielded a much smaller particle size (under $150 \mathrm{~nm}$ ) compared to the one obtained by the formulation that captured the purified propiconazole (over $1.7 \mu \mathrm{m}$ ), which also had the biggest variation among repetitions. Likewise, the formulations that worked with Prosan ${ }^{\circledR}$ showed a much higher Zeta potential (over $50 \mathrm{mV}$ ), denoting a very stable suspension, while the system that worked with purified propiconazole showed a low value (under $5 \mathrm{mV}$ ), conferring the nanospheres a tendency to agglomerate. Both the small particle size and high zeta potential of the Prosan ${ }^{\circledR}$ systems could be attributed to the presence of stabilizers and emulsifiers in the commercial formulation. In regard of the encapsulation efficiency, Formulation \#3 had the highest of the 3 systems, obtaining average values over $40 \%$. Fig. 2 shows the morphology of the formulations 3 and 6 to compare the difference in size of the systems that worked with Prosan ${ }^{\circledR}$ and purified propiconazole, respectively, obtained using a Jeol scan electron microscope, model JSM-IT300. For both systems the particles showed a semispherical shape with a smooth surface, the main difference being that formulation \#6 had particles over ten times bigger than those obtained by the formulation \#3. Since formulation \#3 presented a small particle size, high suspension stability, and the highest encapsulation efficiency, this was the system selected to perform the antifungal activity tests with.

Table 2. Average particle size, zeta potential, and encapsulation efficiency for the formulations 3,5 and 6 .

\begin{tabular}{|c|c|c|c|}
\hline $\begin{array}{c}\text { Formulation (carrier and } \\
\text { encapsulated agent) }\end{array}$ & $\begin{array}{c}\text { Particle size } \\
(\mathbf{n m})\end{array}$ & $\begin{array}{c}\text { Zeta Potential } \\
(\mathbf{m V})\end{array}$ & $\begin{array}{c}\text { Encapsulation efficiency } \\
(\mathbf{\%})\end{array}$ \\
\hline 3 (PLA/Prosan $\AA)$ & $146.28 \pm 73.5$ & $65.93 \pm 13.54$ & $42.72 \pm 9.98$ \\
\hline 5 (PLGA/Prosan $\AA$ ) & $90.27 \pm 34$ & $50.76 \pm 2.28$ & $21.66 \pm 8.84$ \\
\hline 6 (PLGA/Propiconazole) & $1715.66 \pm 603.78$ & $4.46 \pm 1.77$ & $31.58 \pm 5.9$ \\
\hline
\end{tabular}




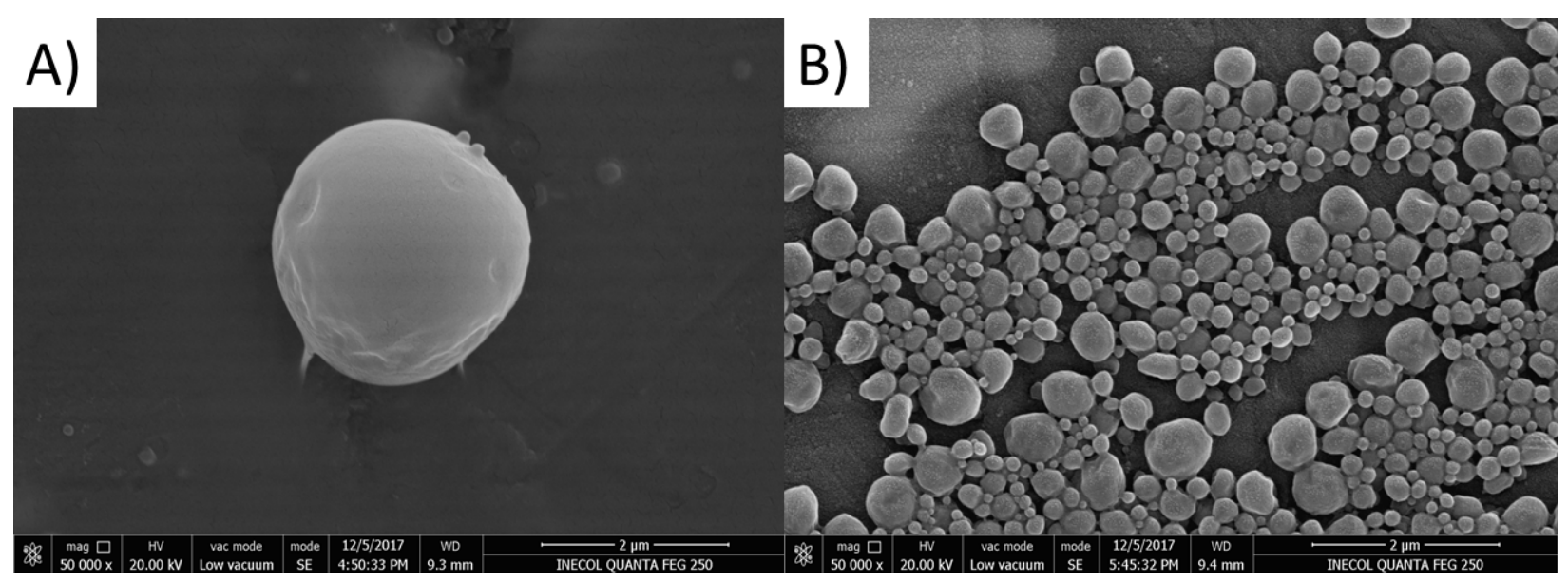

Fig. 2. Morphology of the nanospheres encapsulating fungicide at 50,000X: A) Formulation \#3, encapsulating purified propiconazole; B) Formulation \#6, encapsulating Prosan ${ }^{\circledR}$.

\section{Infrared spectroscopy (FTIR)}

Fig. 3 shows the infrared spectra for PLA, pure propiconazole and propiconazole that was encapsulated and then released in ethanol, to discard any possible reaction between the active ingredient and the carrier during the nanoencapsulation process. The spectra were obtained using an Agilent Technologies infrared spectroscope, model Cary 660, with a PIKE Technologies ATR, model Gladia. The only change detected is the augment in intensity of the carbonyl peak for the released propiconazole. This is attributed to PLA partially solubilized in the ethanol used as release medium.

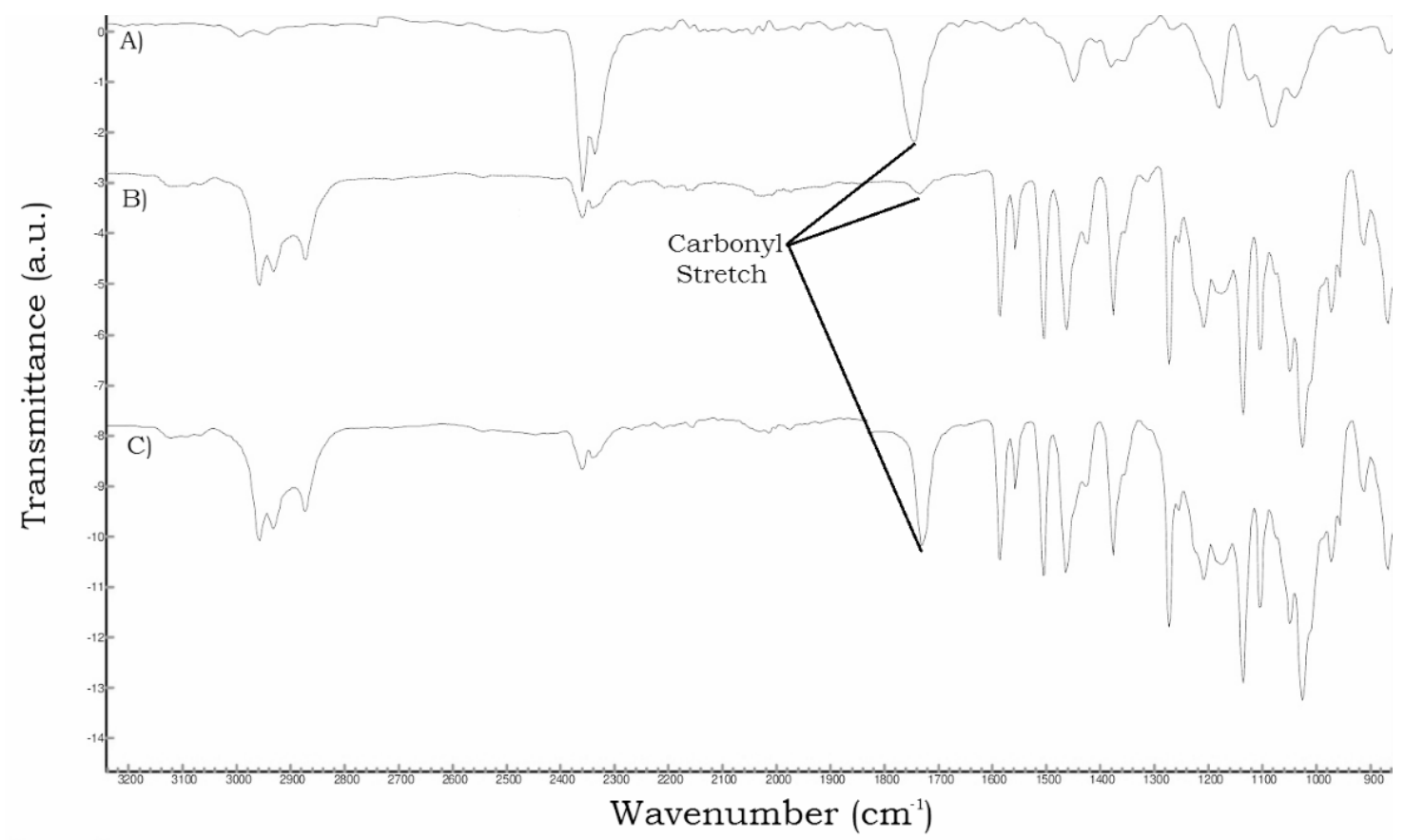

Fig. 3. FTIR spectra of A) PLA, B) Propiconazole, and C) Propiconazole released from nanocapsules. 


\section{Release profile}

In fig. 4 is noted a slower release of the propiconazole load from the dialyzing of nanocapsules than that form the commercial formulation. While the commercial formulation dialyzed 50 and $90 \%$ of the propiconazole in approximately 5 and 30 hours, respectively, it took the nanoencapsulated propiconazole almost twice as much time to dialyze the same percentage of load (11 and 55 hours, respectively). Both systems reached $100 \%$ of dialyzed load by the end of the experiment (104 hours).

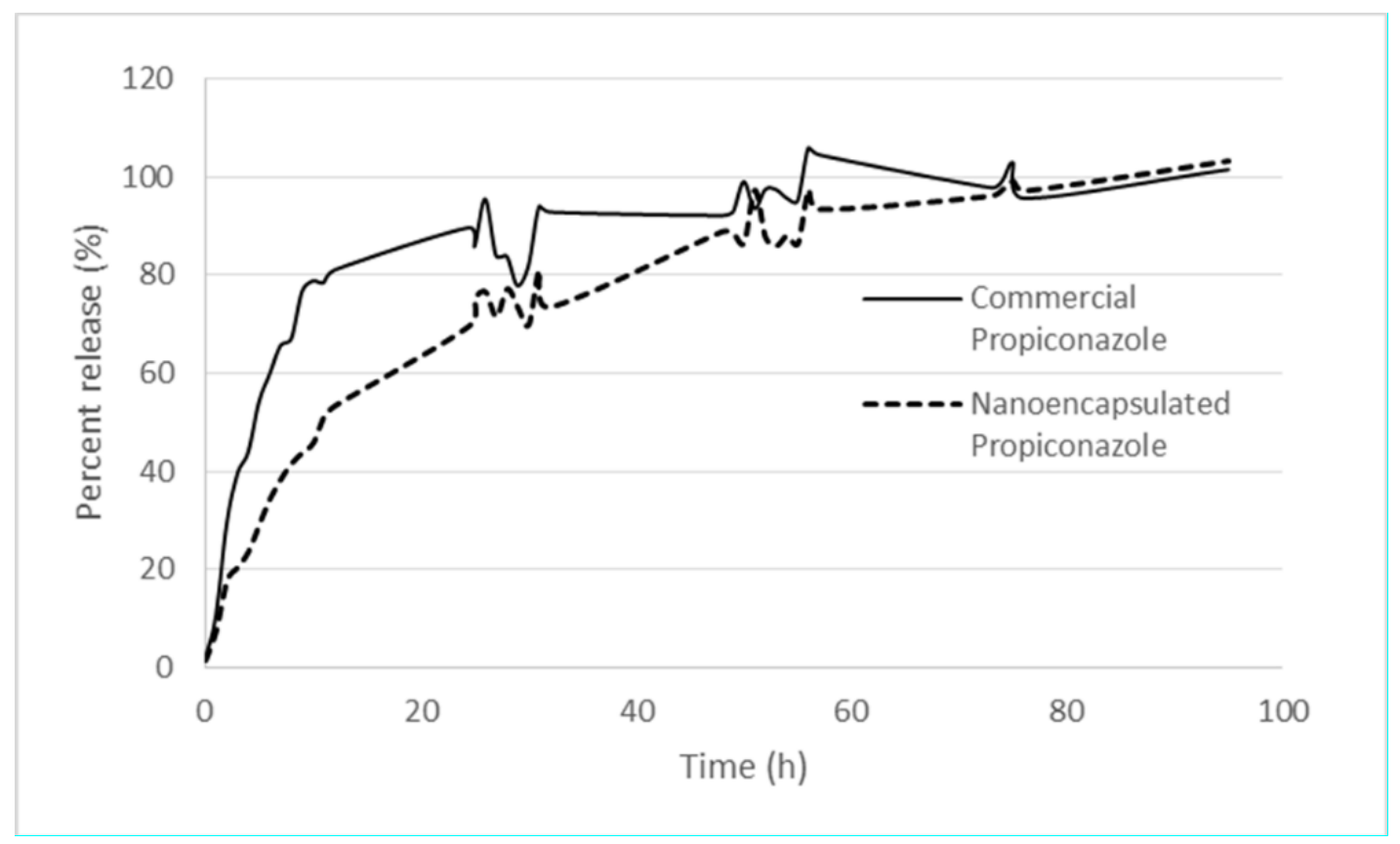

Fig. 4. Profile release for the commercial and nanoencapsulated propiconazole formulations, respectively.

\section{Antifungal activity}

The growth morphology of the Fusarium solani strain at different conditions is shown in Fig. 5. The F. solani strain that grew in PDA produced abundant whitish cottony mycelium (INECOL_BM-04 strain) with pale yellowish pigmentation (reverse side). In contrast, the morphology of the fungus was different when it grew in the presence of the fungicide in both the positive control and the nanoencapsulated material. The coloration changed to reddish brown and the fungi had a non-geometric growth, suggesting a stress in the fungus, moreover this pigmentation and the amorphous growth was accentuated in the treatment with the nanoencapsulated fungicide. Fig. 6 shows the GIP for formulation \#3 compared to the positive control and the empty PLA nanoparticles. The nanoencapsulated fungicide showed an increased GIP in relation to the positive control. Such increase was of $5 \%$, reaching a GIP of nearly $74 \%$ for the formulation \#3. PLA nanospheres showed a GIP of nearly $55 \%$, explaining why there is antifungal activity when using nanoencapsulated propiconazole even if the active ingredient is not fully available at the beginning of the experiment. 


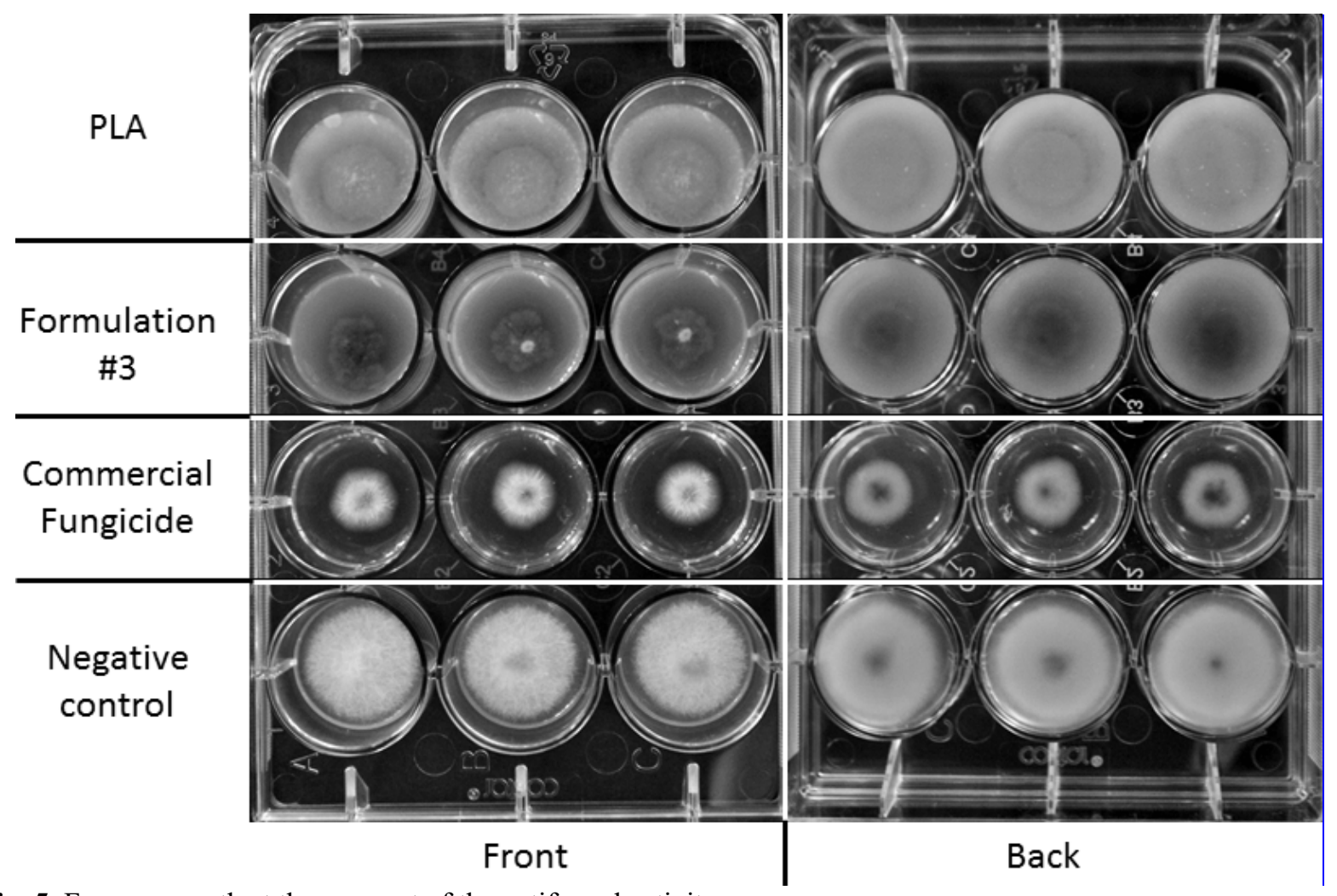

Fig. 5. Fungus growth at the moment of the antifungal activity measure.

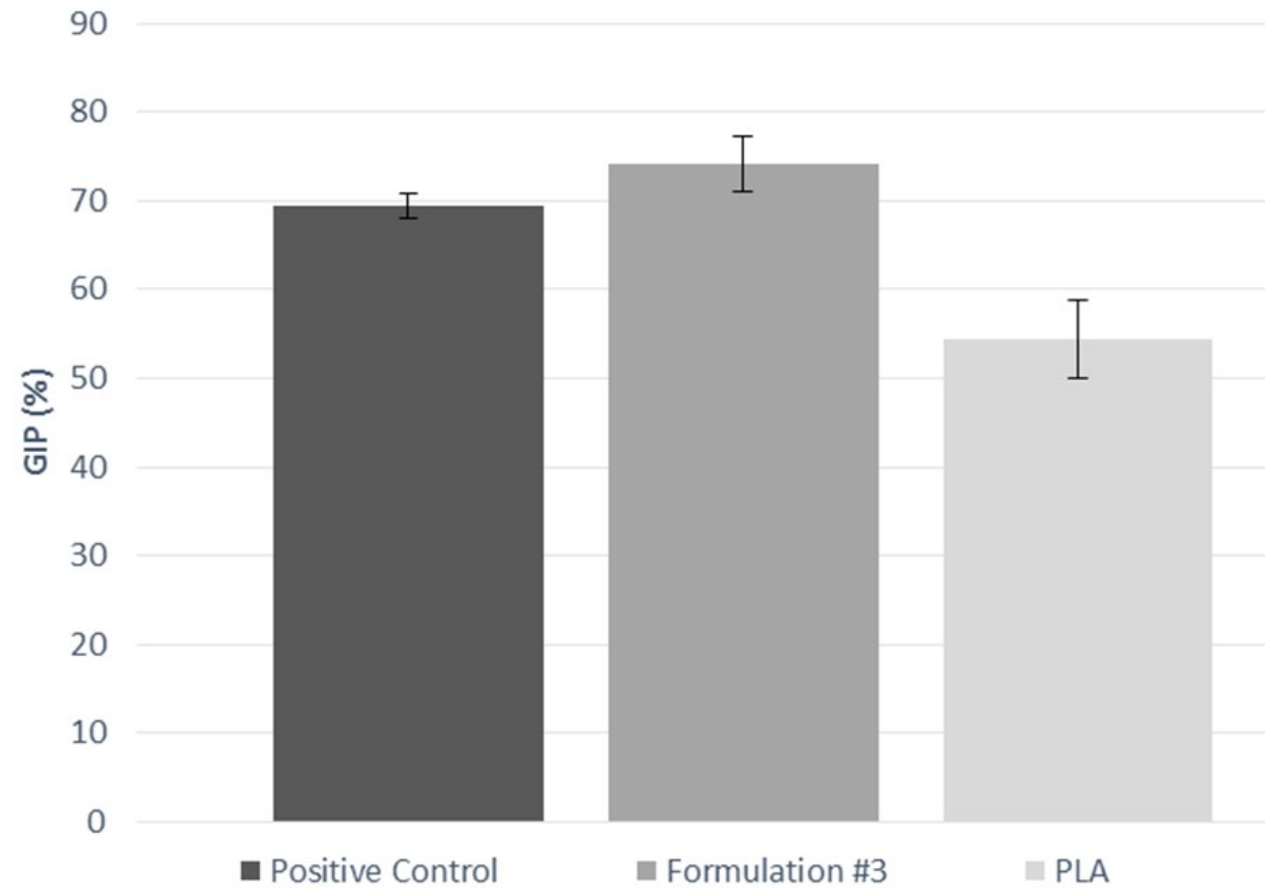

Fig. 6. GIP values for positive control, PLA nanospheres, and formulation \#3. 


\section{Conclusions}

It was able to encapsulate the active ingredient propiconazole in nanospheres of biodegradable polymers, both as a commercial formulation and as a purified compound. Nevertheless, the system that captured purified propiconazole showed a bigger particle size and a very low Zeta potential, which could provoke precipitations in a shorter period, reducing its shelf life and ability to be dispersed in water, condition required for its application in the field. As the commercial formulation used in the experiments is an emulsifiable concentrate, it most likely contains a surfactant that enables the systems to obtain a smaller drop size during the emulsification step, as well as conferring a higher zeta potential, since it is the agent that avoids the agglomeration of the organic droplets during the emulsification process, and then of the nanoparticles once the organic solvent has been removed. Of the two formulations that used Prosan ${ }^{\circledR}$ as encapsulated agent, both showed a small particle size and high Zeta potential but being the PLA the polymer that showed the highest encapsulation efficiency. Formulation \#3 presented a system with a small particle size, an excellent zeta potential and a slightly superior GIP in relation with pure propiconazole, obtaining a fungicide that can be dispersed in water without the need of organic emulsifier agents. The degradation of the carrier is preferred as it won't generate pollution but doesn't play an important role in the release of the active ingredient in this system. In addition to the reduction of the environmental impact, these characteristics could also promote the mobility of the fungicide inside the tree.

\section{Acknowledgements}

The authors thank Greta Hanako Rosas Saito (Instituto de Ecología A. C.) for the technical support on the acquisition of SEM images. This project was supported by Fondo Sectorial para la Investigación, el Desarrollo y la Innovación Tecnológica Forestal (2015-C01-265677).

\section{References}

1. Cano Robles, F. K.; Mendoza Cantú, A.; Revista Bio Ciencias 2017,4(3), 164-178. DOI: 10.15741/revbio.04.03.03

2. Xue, J.; Zan, G.; Wu, Q.; Deng, B.; Zhang, Y.; Huang, H.; Zhang, X.; Inorg. Chem. Front. 2016, 3(3), 354364. DOI: $10.1039 / \mathrm{C} 5 \mathrm{QI00186 \textrm {B }}$

3. Bramhanwade, K.; Shende, S.; Bonde, S.; Gade, A.; Rai, M.; Environ. Chem. Lett. 2016, 14(2), 229-235. DOI: $10.1007 / \mathrm{s} 10311-015-0543-1$

4. Singh Duhan, J.; Kumar, R.; Kumar, N.; Kaur, P.; Nehra, K.; Duhan, S.; Biotechnology Reports 2017, 15, 11-23. DOI: 10.1016/j.btre.2017.03.002

5. Eatough, M.; Kabashima, J.; Eskalen, A.; Dimson, M.; Mayorquin, J.; Carrillo, J.; Hanlon, C.; Paine, T.; J. Econ. Entomol. 2017, 110(4), 1611-1618. DOI: 110. 1611-1618. 10.1093/jee/tox163.

6. Ghormade, V.; Deshpande, M. V.; Paknikar, K. M.; Biotechnol. Adv. 2011, 29, 792-803. DOI: 10.1016/j.biotechadv.2011.06.007.

7. Mogul, M. G.; Akin, H.; Hasirci, N.; Trantolo, D. J.; Gresser, J. D.; Resour. Conserv. Recy. 1996, 16, 289-320.

8. Lavicoli, I.; Leso, V.; Beezhold, D. H.; Shvedova, A. A.; Toxicol. Appl. Pharm. 2017, 329, 96-111. DOI: 10.1016/j.taap.2017.05.025

9. Mishra, S.; Singh, R.; Singh, A.; Keswani, C.; Naqvi, A. H.; Singh, H. B.; Yu, J.-H.; Plos One 2014, 9(5): e97881. DOI: 10.1371/journal.pone.0097881

10. Nuruzzaman, M.; Mahmudur Rahman, M. M.; Liu, Y.; Naidu, R.; Agric. Food Chem. 2016, 64, 1447-1483. DOI: 10.1021/acs.jafc.5b05214

11. Auffan, M.; Rose, J.; Bottero, J.-Y.; Lowry, G. V.; Jolivet, J.-P.; Wiesner, M. R.; Nat. Nanotechnol. 2009, 4, 634-641. DOI: 10.1038/nnano.2009.242.

12. Grillo, R.; dos Santos, N. Z. P.; Maruyama, C. R.; Rosa, A. H.; de Lima, R.; Fraceto, L. F.; J. Hazard. Mater. 2012, 231-232, 1-9. DOI: 10.1016/j.jhazmat.2012.06.019

13. Yan, J.; Huang, K.; Wang, Y.; Liu, S.; Chin. Sci. Bull. 2005, 50, 108-112. DOI: 10.1360/04wb0077 
14. Nair, R.; Varghese, S. H.; Nair, B. G.; Maekawa, T.; Yoshida, Y.; Kumar, D. S.; Plant Sci. 2010, 179, 154-163. DOI: 10.1016/j.plantsci.2010.04.012

15. Zhang, J.; Li, M.; Fan, T.; Xu, Q.; Wu, Y.; Chen, C.; Huang, Q.; J. Polym. Res. 2013, 20, 1-11.

16. Lee, J.; Moon, J.; Jeong, J.; Kim, M.; Kim, B.; Choi, M.; Kim, J.; Ha, C.; Macromol. Res. 2016, 24(8), 741-747. DOI 10.1007/s13233-016-4100-y

17. Chuensangjuna, C.; Pechyenb, C.; Sirisansaneeyakula, S.; Energy Procedia. 2013, 34, 73 - 82. DOI: 10.1016/j.egypro.2013.06.735

18. Hwisa, N.; Katakam, P.; Rao, B.; Kumari, S.; VRI Bio.l Med. Chem. 2013, 1(1), 1, 8-22. DOI: 10.14259/bmc.v1i1.29 